\title{
Algunos antecedentes históricos, socio-culturales de las bebidas alcohólicas en Ecuador dirigido a los estudiantes de arte y turismo
}

\author{
Some historical and socio-cultural background of alcoholic \\ beverages in Ecuador aimed at art and tourism students
}

\section{Dallas Glenda Hormaza Muñoz}

Universidad Laica Eloy Alfaro de Manabí, Manta, Ecuador

dallasglenda@gmail.com
Recibido 14/04/2020 Revisado 25/06/2020

Aceptado 02/07/2020 Publicado 31/07/2020

\section{Resumen:}

Este trabajo pretende evidenciar la gran importancia e interés que gira alrededor de las bebidas alcohólicas en Ecuador para la construcción de obras de arte y la recreación argumentada desde nuestros legados culturales y ancestrales que se hibridizan con toda la influencia de la contemporaneidad. Ver el aporte que se establece en las danzas cuyo proceso ha sido la investigación cultural para representarlas en la escena con temas relacionados a estas bebidas, unas ancestrales, otras heredadas y el divorcio de este conocimiento con los estudiantes de Turismo, determinó la necesidad de recoger algunos antecedentes mediante observación, análisis de contenidos, entrevistas, que sirvieran no solo a la población en general sino de manera específica a los estudiantes de turismo y arte por su necesidad de apoyos y fundamentos para continuar recreando y desarrollando nuevas composiciones y sabores a partir del conocimiento de sus legados registrados en las bebidas alcohólicas: históricos, culturales y sociales.

\section{Abstract:}

This work aims to demonstrate the great importance and interest that revolves around alcoholic beverages in Ecuador for the construction of works of art and the recreation argued from our

Sugerencias para citar este artículo,

Hormaza Muñoz, Dallas Glenda, (2020). Algunos antecedentes históricos, socio-culturales de las bebidas alcohólicas en Ecuador dirigido a los estudiantes de arte y turismo. Tercio Creciente, 18, págs. 57-73, https://dx.doi.org/10.17561/rtc.n18.4

HORMAZA MUÑOZ, DALLAS GLENDA. Algunos antecedentes históricos, socio-culturales de las bebidas alcohólicas en Ecuador dirigido a los estudiantes de arte y turismo. Tercio Creciente, julio 2020. $\mathrm{n}^{\mathrm{o}}$ 18, pp. 57-73, https://dx.doi.org/10.17561/rtc.n18.4 
ISSN: $2340-9096$

https://dx.doi.org/10.17561/rtc.n18.4

cultural and ancestral legacies that hybridize with all influence of contemporary times. Seeing the contribution that is established in dances whose process has been cultural research to represent them on them on the scene with related to these drinks, some ancestral, others inherited and the divorce of this knowledge with some Tourism students, determined the need to collect some background through observation, content analysis, interviews, which would serve not only the general population but specifically tourism and art students for their need for supports and foundations to continue recreating and developing new compositions and flavors from the knowledge of their registered legacies in alcoholic beverages: historical, cultural and social.

Palabras Clave: : bebidas alcohólicas, antecedentes históricos, culturales y sociales, legado, herencia.

Key words: alcoholic beverages, historical, cultural, social, background, legacy, inheritance..

Sugerencias para citar este articulo,

Hormaza Muñoz, Dallas Glenda, (2020). Algunos antecedentes históricos, socio-culturales de las bebidas alcohólicas en Ecuador dirigido a los estudiantes de arte y turismo. Tercio Creciente, 18, págs. 57-73, https://dx.doi.org/10.17561/rtc.n18.4

HORMAZA MUÑOZ, DALLAS GLENDA. Algunos antecedentes históricos, socio-culturales de las bebidas alcohólicas en Ecuador dirigido a los estudiantes de arte y turismo. Tercio Creciente, julio 2020. $\mathrm{n}^{\mathrm{o}} 18$, pp. 57-73, https://dx.doi.org/10.17561/rtc.n18.4 


\section{Introducción}

Cuando escuchamos la palabra bebida, es natural y agradable imaginarnos un refrescante vaso de agua, pero a medida que va transcurriendo el tiempo este vocablo evoluciona a consecuencia de cómo se le va agregando, a su contenido, diversas frutas, sabores, colores; también, sometiéndola a destilados y fermentados, que han dado paso a la obtención de bebidas hidratantes, curativas, alcohólicas, heladas, calientes, consumidas de acuerdo al gusto y necesidad de quien la procure (Gallegos \& Santana, 2018).

Adentrarse a probar, paladear u olfatear el mágico paraíso de una bebida alcohólica servida en una frágil botella, vaso o copa de cristal, es una costumbre que se practica desde tiempos inmemorables, con el fin de calmar la sed de monarcas, gobernantes, obreros, esclavos, parias y pobladores de cada región del mundo, que embriagados por el deseo de festejar, conmemorar, celebrar o compartir momentos especiales, se fue escribiendo una historia que cuenta los grandes acuerdos, pactos, compromisos y uniones que se hicieron en su honor. Con solo mirar las obras pictóricas de reconocidos autores que hacen referencia al hecho de beber: "La última cena" Leonardo da Vinci (1498), "Almuerzo de remeros" Pierre-Auguste Renoir (1880) "Los borrachos" y "almuerzo de campesinos" Diego Velásquez (1628),

\section{El Panorama en Latinoamérica}

Por un momento veamos que se presenta en Latinoamérica, sobre las bebidas populares ancestrales. El tequila (fermentación y destilado de agave) es la más popular en México, el mojito (mezcla de ron, azúcar, lima, hojas de menta y más hierbas) es parte de la identidad cubana, la caipiriña (fermentación y destilación del jugo de la caña de azúcar, con lima y azúcar distingue a Brasil, el pisco (destilación de uvas, y agregado de clara de huevo, jugo de limón y azúcar) fue introducido al Perú por grupos de extranjeros en el siglo XVI y desde allí es un signo representativo que diferencia a ese país. Hago este señalamiento para reforzar la idea de que en cada una de nuestras naciones, el pueblo, usa alguna bebida fermentada y destilada para alegrar el espíritu y también para sanar dolencias corporales de forma efectiva.

En nuestra geografía latinoamericana las bebidas ancestrales tienen su origen en el indigenado y surgieron por la siembra y cosecha de la caña, que se dio en las haciendas de la época de la colonia y los inicios de la república, sin dejar de mencionar a las transportadas por los peninsulares. Siendo parte importante, del consumo de estas bebidas, los rituales, lugares donde se degustaban esos néctares, las redes de elaboración o fabricación, sin olvidar el legendario contrabando de aquellas bebidas espirituosas que se consumía en la colonia (Gomezjurado, 2014, p.287) (Gallegos \& Santana, 2018) 
Para (Gallegos \& Santana, 2018) en nuestra América, el inicio del consumo de una bebida alcohólica que tiene como principal ingrediente la caña de azúcar, es el guarapo, proveniente de las Islas Canarias, hace más de 500 años y que llegó al país en el período colonial y vendiéndose en sitios secretos.

\section{Lo que acontece en Ecuador}

Hablando de Ecuador, en la zona de Coaque, costa de nuestro país, de acuerdo a lo que cuenta un viajero al inicio del siglo XVII, los comuneros elaboraban cinco o seis formas de bebidas diferentes: "unas de maíz, otras de plátano, otras de raíz, otras de caña y otros compuestos, que ninguno nos pareció mal" (Herrera y Montemayor, 1947,70) (Patiño, 1990)

También el cronista Cieza de León da a conocer que el "vino" preparado por los indios de Puerto Viejo era dado como ofrenda a sus muertos (Marcos \& Hidrovo, 2010) (Pág.204)

Con el paso de los años, va evolucionando el consumo de la caña de azúcar, aparecen las formas rudimentarias de destilarla para obtener una bebida embriagadora, conocida también con el nombre de aguardiente, que sigue siendo consumida de manera pura, añejada, aromatizada o mezclada. (Dueñas, 2010) Esta misma autora señala que en 1605, la mano de obra laboral estaba formada por indios que trabajaban en las chácaras por un real al día y la comida; los que constituían las mitas ganaban 9 reales y medio por quincena y la comida; y los yacones, como peones de los españoles, 12 pesos cada año. Hubo otros que trabajaron como esclavos, cinco de estos laboraron en un trapiche particular.

Hoy en día, una práctica que se acostumbra dentro de la dieta, como parte del mestizaje cultural, es el consumo de aguardiente, que además de ser una bebida que embriaga, es una bebida que estimula y que tiene virtudes medicinales, lo que amplía y regula una aprobación mayor que el vino por parte de la población (Patiño 1990).

Por los registros encontrados, se conoce que la caña de azúcar, es una planta que crecía en las zonas tropicales y su desarrollo era mejor y mayor cuando se presentan temperaturas altas. Con esta planta se formaban grandes cañaverales, que nacían y se desarrollaban de forma natural y abundante, con altos follajes verdes que son sostenidos por un fuerte pero delgado tallo. La parte comestible está compuesta por un tallo fibroso, de varios metros de altura, de un verde intenso, en la parte posterior y, la parte interior contiene una pulpa sólida, blanquecina, esponjosa y muy dulce, que tiempo después fue altamente apetecida para extraer de ella el azúcar.

Estas evidenciables citas, que diferentes autores señalan, nos llevan a reconocer que el consumo de bebidas embriagantes en el territorio ecuatoriano, tiene una antigüedad que se 
relaciona con el período prehispánico, y que ha sido atribuida a la relación hombre - divinidad, hombre - naturaleza, hombre - salud corporal. Los datos encontrados dan fe de que palabras como: trapiche, destilación, añejado, encierran la insipiente, pero no menos importante empleabilidad de la caña de azúcar, el maíz, el plátano, raíces, yuca y otras plantas que fermentadas se consumían de manera general. De allí en adelante la historia está escrita por región: En las frías montañas de los Andes, es muy popular y frecuente el consumo del canelazo, una costumbre, que se va heredando de una generación a otra, ahora también en la Costa ecuatoriana, cuya preparación consiste en hervir agua de canela, naranjilla, panela (sirve como endulzante) y luego agregarle alcohol de acuerdo al gusto de los consumidores. Al tomarse de forma tibia o caliente, calma el frío y espanta el sueño. El historiador Javier Gomezjurado Zevallos narra que esta bebida, por ser de sencilla y barata elaboración, seguramente fue consumida, desde la época colonial, por las clases sociales y económicas bajas y medias.

También en la región andina se conoce como punta o guarapo, al modo ancestral de procesar, de manera pura, el alcohol extraído de la caña de azúcar, que, entre sus múltiples presentaciones, el más famoso es el Pájaro Azul, proviene concretamente de la provincia de Bolívar y debe su nombre al tono azulado que adquiere en su obtención. La aceptación que tiene lo ha llevado a que sea exportado a los países vecinos de Perú y Colombia. Para terminar de citar la más relevante de estas clases de bebidas, anotaremos el consumo que se le da en la Costa ecuatoriana y expresaremos que el más conocido, es el aguardiente o puro, que atrae la atención mayoritaria de los pobladores de la zona rural. En Manabí, por ejemplo, el que goza de mucha aceptación es el aguardiente compuesto, cuya preparación consiste en agregar al licor especias dulces (canela, clavo de olor, pimienta dulce, anís estrellado) hierbas (ruda, calaguala, saragoza) miel de abeja y frutas. El quemado para las paridas, da cuenta de una forma particular de beber el aguardiente compuesto, después de poner la porción que se va a consumir, en un recipiente que resista el fuego y luego prenderle llama hasta que esta se evapore totalmente (flameado) se procede a servirlo cuando su estado entibie.

En el Ecuador actual, podemos anotar que las bebidas alcohólicas, fabricadas con aguardiente mayoritariamente consumidas son: Caña manabita, Cristal, Pájaro azul, Licor del valle (Sangolqui) Anisado Patito, Licor del mono o guagua montado.

Otra bebida que goza de gran aceptación y popularidad en el entorno andino es la chicha, fruto del maíz fermentado (o chicha de jora), que, siendo sometida a una rigurosa preparación, formó parte de la gastronomía y religiosidad ancestral, en la Sierra de Ecuador. Suplantaba regularmente al agua y a cualquier otra bebida casera, igualmente al vino en las celebraciones familiares, lo que hacía muy requerida su elaboración. La chicha se constituyó en la bebida de mayor consumo entre los millones de habitantes del Tawantinsuyo (Ariansen, https://www.historiacocina.com/paises/articulos/peru/chicha.htm, s.f.)

La chicha tiene la particularidad de que su preparación conserva, casi los mismos ingredientes que hace 3000 años (www.culturaypatrimonio.gob.ec) ha sido parte de la historia 
de nuestro país, en cuanto a costumbres y tradiciones que llamaron la atención de cronistas e investigadores que escribieron sobre la cosmovisión andina.

El historiador (Loor, 1956) cita en la Pág. 130, a Cieza de León, indica que cuando sepultaban a un ser querido acompañaban su cuerpo con joyas, alimentos preparados y vasijas de chicha.

También, antes de echar tierra sobre la urna, ubicaban una caña guadúa, lo suficientemente gruesa, que conectara la tumba con la superficie, que les permitiera tirar de vez en cuando chicha, conocida igualmente como azua o también como vino de maíz, para que el fallecido beba y se embriague. Este mismo autor hace otra referencia al respecto, citando en la Pág. 139, a Bartolomé Ruíz, al describir que, en estas tierras, las tareas agrícolas y la preparación la chicha era un oficio mayoritariamente de las mujeres.

El consumo de chicha todavía se mantiene en nuestro país, en la Costa, Sierra y Oriente, con la diferencia que la preparación va de acuerdo a cada región y los ingredientes que rodean al maíz también varían. En la Sierra se la sigue consumiendo en las fiestas populares, como el Inti Raymi, en la Costa para celebrar cumpleaños de manera tradicional, igualmente en lugares de concurrencia popular, como los mercados. En la Amazonía es parte de rituales de bienvenida a los visitantes, también en ocasiones que se consideran especiales, siendo su principal ingrediente la yuca. La chicha en la Provincia de Manabí, tiene un sabor agridulce, se la bebe con mucho hielo picado, es espesa y su color es amarillo.

Con el paso del tiempo aparecieron: el rompope, la mistela, como bebidas tradicionales del país.

\subsection{La cerveza}

Es otra bebida alcohólica que también tiene sus orígenes en la época antigua, con la particularidad de que su consumo o uso humano, en este siglo, rebasa a las demás. De la misma manera que la preparación del pan y de cualquier producto económico encargado a la ama de casa, la elaboración de la cerveza estaba primitivamente bajo la responsabilidad de ella, hasta que se convirtió en un producto industrializado, cuando ya es manejado directamente por el hombre (Martínez J. , 2006) Tiene una antigüedad de más de 5000 años y era conocida como "siraku" en la lejana Mesopotamia, donde se conocen sus inicios más distantes, elaborada a base de granos fermentados, con gran aceptación entre la población. Para el siglo VI a.C. es consumida por primitivas tribus germánicas, pero fue recién en el año 766, cuando se construyó la primera fábrica de cerveza y en 1645, cuando en las tribus de Alemania se la conoce como "Mer", néctar divino y tradicional (mexicanos en Alemania, 2016). Esquilo y Sófocles, en escritos, hacen mención de esta bebida que no gustó ni a romanos ni a griegos (cerveza, s.f.). 
ISSN: 2340-9096

https://dx.doi.org/10.17561/rtc.n18.4

La cerveza es como el chocolate, conserva su sabor en el paladar. Beberla con las comidas, aliviana y refresca el picante de los alimentos, de la misma manera lo hace con aquellos que tienen mucho condimento; se lleva bien con cualquier ensalada, realzando el gustillo de las verduras amargas; desvanece del paladar la sensación de grasa que dejan algunos productos alimenticios aceitosos; la cerveza también pueden constituirse en ingrediente para simplemente realzar los sabores de alimentos que se brindan con ella (Peralta, 2013)

Sin ningún tipo de prejuicio su consumo se da en todos los estratos sociales, económicos y generacionales. Puede adquirirse en un kiosco, tienda, supermercado, bar, garita, discoteca, restaurante u hotel. El precio que se paga por ella no es elevado y las hay de fábrica, artesanales, nacionales y extranjeras. Desde mi punto de vista, la cerveza está ligada a los sentimientos humanos que acompañan al hombre latinoamericano: se la bebe en los ratos de gozo infinito como un logro alcanzado, una meta cumplida, un bien obtenido; en instantes de calor sofocante y sed intensa; pero, también es buena compañía para apaciguar las tristezas, las penas de amor, las desesperanzas, el agobio diario.

El arte, máxima expresión creativa del hombre, no se ha olvidado de tomarla en cuenta, a través de la música, artistas populares le han cantado: Alci Acosta "Una cerveza", Rodolfo Aicardi "Una cerveza", Elvis crespo "La cerveza" son un claro ejemplo de ello.

Pero si el buen gusto literario acompaña al bebedor, quizá disfrute recordando al poeta, narrador y crítico estadounidense, Edgar Allan Poe, con sus "versos a la cerveza":

Escancia la mezcla de espuma y ámbar,

que yo vaciaré de nuevo este vaso.

Tan hilarantes visiones trepan

por las estancias de mi cerebro,

tan raros pensamientos, tan queridas fantasías

vienen a mi y se desvanecen,

que ¿a qué preocuparse por el paso del tiempo?

Bebo cerveza hoy. 
O quién sabe al poeta nicaragüense Ernesto Cardenal con su inspiración: Como latas de cervezas vacías.

\author{
Como latas de cervezas vacías \\ y colillas de cigarrillos apagados \\ han sido mis días.
}

Pero de qué está compuesta esta bebida que gusta a gran cantidad de pobladores del planeta. Toda cerveza incluye en su composición varios ingredientes, algunos imprescindibles para la obtención del producto: Lúpulos, cebada, levadura y por supuesto agua (Terán, 2015).

EL lúpulo es una planta que vino de Europa, herbácea, su fruto es parecido a la piña y está recubierto de un polvo muy fino, amargo, que es lo que se usa para darle ese sabor especial a la bebida. (Martínez J. , 2006) Señala que la utilización de lúpulo, se origina con los finlandeses y de manera poética en uno de sus obras literarias: Kalewala, lo menciona como materia prima que aromatiza la cerveza.

La cebada es una gramínea (grano) como lo es el arroz y el maíz, que se cultiva a gran escala en el mundo entero, debido a que su consumo es también mayoritario. El registro de su existencia se remonta a tiempos bíblicos, a restos arqueológicos, a la historia antigua (Grecia, Roma y Egipto) y el uso más frecuente que ha tenido es en la elaboración de pan. Como ingrediente en la elaboración de cerveza, se la "maltea" (acción de sacarle el almidón que es posible de desaparecer) del grado de tostado depende el color final de la cerveza.

En tiempos de la Edad Media, siglos XIV y XV, la preparación de la cerveza, fue encargada mayoritariamente a los monasterios y las amas de casa en los hogares del norte de Alemania, con resultados de prosperidad económica, hasta el punto de exportarla, siendo producidas principalmente en Hamburgo y Danzig (Martínez J. , 2006)

Con respecto a nuestro país, (Terán, 2015) expresa que en la actualidad hay agricultores que se dedican a la producción de cebada en provincias como Imbabura, Pichincha, Carchi, Tungurahua y Cotopaxi, siendo una producción para consumo interno, más no para el comercio con otras empresas que demandan de este producto como materia prima para la elaboración de galletas, vino, postres, pan o malta. Es necesario recalcar que no hay empresas que se dediquen a la producción de malta. En contraposición, de acuerdo a lo que citan (Villacreses, Elena; Rivadeneira, Miguel, 1996) La cebada en los actuales momentos, siguiendo al maíz, es el cereal que más se distribuye en la Sierra, su consumo radica primordialmente en la alimentación de la población y en la industria cervecera, destinada una proporción pequeña en hierba para el ganado. Es decir, que el desarrollo e industrialización de la cerveza, ha tenido toda la apertura para convertirse en lo que es hoy; una fuente de ingresos económicas que permite la 
empleabilidad de muchos ecuatorianos que trabajan en la producción, embotellamiento, distribución, comercialización y venta en tiendas y bares, del producto.

La levadura sirve para obtener el grado de fermentación que como mínimo debe durar entre una a tres semanas. Al mosto (líquido remojado, todavía dulce) se le agrega la levadura, que, de una manera rápida, al mezclarse con el oxígeno que encuentra en la sustancia empieza a consumir el azúcar y a transformarla en alcohol y en anhídrido carbónico (CO2). Fuente: https://www.caracteristicas.co/cerveza/\#ixzz68UZ15fCu

Quienes la elaboran de manera artesanal opinan que los elementos indispensables son: agua, lúpulo, malta y levadura, todos estos productos también dependen de la mezcla y del tipo de cerveza que se quiera obtener; por ejemplo: los lúpulos tiene diferentes aromas que van desde los florales hasta los cítricos, cambiando enteramente el gustillo de la cerveza artesanal que se quiera conseguir (Brush \& Almeida, 2019).

Haciendo una remembranza de la llegada de la cerveza a este continente, señalaremos que, en Argentina, fueron los alemanes quienes iniciaron este negocio. Con la construcción de la fábrica, se estableció una importante sociedad de residentes de Alemania, siendo la tercera en el país, manteniendo buenas relaciones con todos los directivos y los empleados superiores de la cervecería, que casi siempre eran también de origen alemán. Para citar un caso, el maestro cervecero Hellmut Roempler, fue contratado y traído desde Alemania para dirigir técnicamente la fábrica hasta el año 1900 (Russo, 2008). La familia Bemberg ayudó a impulsar al sector industrial que prácticamente no existía en el país, creando desde el inicio plazas de trabajo y capacitando la mano de obra. Al principio trajeron desde Europa a los primeros artesanos, que venían de importantes y tradicionales centros cerveceros, hasta conformar comunidades manufactureras locales (Russo, 2008). Ya en los tiempos actuales diremos que en los veinte últimos años su consumo ha crecido considerablemente, desplazando del primer lugar al vino, que es una bebida alcohólica de gran consumo en Argentina. A la par de las innumerables y prestigiosas marcas empresariales, aparecieron también buenas marcas de cervezas artesanales que dieron la oportunidad de elegir a los consumidores. Antares es por ejemplo una marca precursora. Se procesan ediciones especiales dependiendo de la temporada (Craft Beer, 2013).

La industrialización de la cerveza en México goza de una gran tradición, pero fue recién a fines del siglo XIX cuando la empresa cervecera "moderna" echó raíces en ese país. También existieron grandes talleres artesanales dedicados a su elaboración de forma casera, antes de ser industrializada, registrándose la década de 1890, como de pleno desarrollo tecnológico extranjero que se utilizaba para su producción en diversos estados del país. Fue el alemán Santiago Graff quien fundó una empresa familiar de cerveza Toluca y México, de reconocimiento nacional, con un activo de $\$ 10.000$ pesos circulantes. La pequeña empresa comenzó a operar con 13 empleados y para 1885 obtenía una producción diaria que iba de 3 y 5 hectolitros de cerveza proveyendo principalmente la demanda local (Recio, 2004). 
Desde la escritura peruana, Jaime Ariansen Céspedes, cuenta cómo su abuelo Julio Ariansen, alemán, natural de Hamburgo, a finales del siglo XIX se radica en el Cusco, también cita a su padre César, como nacido en esa ciudad, capital de los Incas, quienes fueron técnicos y accionistas de dos reconocidas fábricas de cervezas, por mucho tiempo, lo que hizo de él una persona familiarizada con ese ambiente. Recuerda que era una bebida que se tomaba diariamente en su casa, convirtiéndose en el tema de conversación y el patrimonio económico familiar (Ariansen, Los dioses y la gastronomía, 2013). En este siglo, la gastronomía peruana, que incluye chefs, ferias de impacto internacional, goza de gran prestigio; $y$, entre sus productos de expansión y crecimiento se cuenta a la cerveza. A marcas como la Cusqueña, que tiene gran acogida en el país y se exporta a otros como Chile, Estados Unidos, Japón, Reino Unido y Francia, se suman las que son elaboradas de forma artesanal, cuyo fin es hacer de la cerveza una opción que represente algo más que un refresco. Fue Barbarian, la marca que empezó ofreciéndose en un bar de Lima y en el restaurante del prestigioso cocinero Gastón Acurio. Los emprendedores de este país, tienen el desafío de representar sus orígenes a través del producto, sin olvidar la tradición europea (Craft Beer, 2013).

Colombia une la historia de la cerveza a otra bebida tradicional y fermentada que se conoce en la región: la chicha, hecha con maíz y también con otras plantas originarias del país, como la piña, la papa, la quínoa o yuca. De manera formal, en Colombia se registra la primera cervecería en el año 1826, fundada por el alemán J. Meyer, que lleva su nombre, quien muera asesinado prematuramente, reemplazándolo en el puesto su colaborador Cantrell, que luego vende la cervecería a la Sociedad Martínez y Galinee, en el año 1834 (Hernández, 2019) Otros precursores de la producción cervecera en Colombia, fueron los hermanos alemanes Leo Siegfried y Emil Kopp Koppel, radicados desde 1876 en Santander. Luego formaron la sociedad Kopp y Castello, con los hermanos Santiago y Carlos Arturo Castello y en 1889, empezaron la construcción de la fábrica en Bogotá. Se considera a este negocio como los inicios de la empresa cervecera Bavaria (González, 2014) Hoy en día, la empresa Bogotá Beer Company se define como "la cervecería pequeña más grande de Bogotá", está dedicada a elaborar y vender su propio producto estimulada por el estilo de Europa. También existen otras cervecerías que han recibido premiaciones en el extranjero: Lager, Porter, Ale, Honey (Craft Beer, 2013).

En Chile, la cervecería Kunstman, es una de las empresas artesanales con mayor prestigio en el país, sus fundadores tienen raíces alemanas, al igual que tantos otros que se han dedicado a esta actividad a lo largo y ancho del continente americano. Los Kunstmann, sirvieron de inspiración y emblema a quienes luego trabajaron también en la fermentación artesanal. Una gran parte de estas fábricas cerveceras chilenas están ubicadas en la ciudad de Valdivia (Craft Beer, 2013).

Por ser Brasil un país con gran carga migratoria alemana, en Blumenau, se celebra cada año la Oktoberfest, que es la fiesta alemana de cerveza, más famosa, grande y una de las más populares e importantes de este país y América. Cabe destacar que este festival se realiza en Alemania, Oktoberfest de Munich, cada año, con una asistencia de 6 millones, o más, de visitantes; y, desde 1984, se repite en Blumenau, fortalecida en las raíces alemanas de la gran 
mayoría de sus habitantes y convirtiendo a Sta. Catarina en un referente turístico cultural de esta feria. Cada octubre, por 18 días, las familias de la ciudad, además de la cerveza, presentan danzas, gastronomía, música de origen alemán y es una costumbre que se mantienen desde la llegada de los primeros alemanes a esta región desde el siglo XIX. Fuente: http://www.viajeabrasil.com/. Las marcas más reconocidas son: La Baden, Dama, Bodebrown, Way, Klein, Opa o Colorado. Para poder imaginar el éxito cervecero en Brasil, vale la pena mencionar que en Río de Janiero, en Escapo Lapa Café, se ofrece más de 500 etiquetas (Craft Beer, 2013).

Con respecto a Ecuador, según (Avilés Pino, s.f.), el inicio de esta industria se da en 1886, cuando la Sra. Amalia Flores Jijón de Stagg (hija de Juan José Flores) vende una propiedad, ubicada en el barrio Las peñas, ciudad de Guayaquil, a los Sres. Martín Reimberg Dender y Leonardo Stagg Flores, para montar aquí la Lager Beer Breweries Association. Los señores Stagg y Reimberg abrieron las puertas de la primera fábrica de cerveza en esta ciudad en 9 de octubre de 1887. Pero para (Martínez C. , 2015), en consulta realizada a historiadores, esta industria se inició en nuestro país en el año 1566, con la figura de Fray Francisco Jodoco Rique, del convento de San Francisco, quien llegó de Flandes, ahora Bélgica, convirtiéndola en la primera de latinoamérica.

Después de haber realizado esta breve reseña sobre la llegada de las primeras industrias cerveceras a Latinoamérica, nos viene la curiosidad de querer conocer por qué sus iniciadores fueron influyentes alemanes radicados en nuestros países a partir de la segunda mitad del siglo XIX, cuál fue el momento histórico que se vivió en Alemania que obligó o empujó a muchos de sus habitantes a dejar sus tierras y buscar nuevos senderos. Por historia conocemos a los europeos, como personas que en su esencia humana siempre han sido legendarios aventureros, colonialistas, trotamundos, pero; además de ello, qué otros motivos los destinó a estas tierras americanas.

Se conoce que a partir de esta fecha, a nivel global, se empiezan a notar los efectos de la revolución industrial y la sustitución del liberalismo por el mercantilismo (Estrada, 2013). El abandono del campo para ir a las grandes ciudades como Berlín y Hamburgo aceleró un desequilibro económico puesto que las industrias no tenían empleo para toda la mano de obra que se vino encima, además como eran recién llegados no existía capacidad de vivienda para todos, ocurrió una época de hambre y mucha población joven parada, sin trabajo, se llegó a pagar la mitad del salario básico que se ofrecía en la época (1848-1849), lo que no alcanzaba ni siquiera para comer y para colmo de males los precios de los productos de primera necesidad subían exageradamente. Esta situación afectó mucho a la clase media no únicamente de Alemania sino también de toda Europa, lo que los obligó a decidir entre tres opciones: a) buscar un recurso para utilizar técnicas conformes con un trabajo agrícola intenso y permanecer en sus territorios de origen, b) sustituir el trabajo agrícola por el manufacturero u otra forma de labor y c) emigrar. Y como es evidente, varios optaron por migrar $y$, como resultado, se dio este proceso que fue conocido como la "emigración de la miseria" (Vera de Flaclis, 1994). 
Este impulso económico dado por los grupos inmigrantes que vinieron de Alemania a muchas regiones de latinoamérica, son un referente de la capacidad y el manejo de capital que tenían los alemanes en el ambiente económico internacional. Cabe destacar que estos germanos además de ser intermediarios de un proceso económico, también influenciaron culturalmente dentro de las sociedades receptoras (Estrada, 2013)

Para continuar con el interés central de este artículo, seguiremos contando sobre la evolución que trajo la industria cervecera, específicamente a Ecuador, de acuerdo a lo que señala un estudio realizado por el (Instituto Nacional de Estadísticas y Censos - INEC, 2018) más de 900 mil personas son consumidoras de alcohol en el país. De este porcentaje, el 79,2 tiene gusto por tomar cerveza ante que los demás tipos de bebidas alcohólicas (Brush, Daniel; Almeida, Luis, 2019), esto unido a la producción de cebada que florece en la región interandina dota de todas las facilidades para que se fortalezca la producción. (Brush, Daniel; Almeida, Luis, 2019), a este panorama asoma también la cerveza artesanal, como negocio, apoyada igualmente en las prebendas que reciben las pequeñas empresas, como lo cita el art. 311 de la Constitución:

(...) que el sector financiero popular y solidario se compondrá de cooperativas de ahorro y crédito, entidades asociativas o solidarias, cajas y bancos comunales, cajas de ahorro y que las iniciativas de servicios del sector financiero popular y solidaria y de las micro, pequeñas y medianas unidades productivas, recibirán un tratamiento diferenciado y preferencial del Estado, en la medida en que impulsen el desarrollo de la economía popular y solidaria;

Las cervezas artesanales en Ecuador, clasificadas en: rubia, roja y negra, se distinguen de las industrializadas, porque son más espesas y su grado de alcohol es más alto (puede alcanzar hasta 10 grados) surgió en el año 2010, con el inicio de los primeros emprendimientos que se dieron por parte de familiares y/o amigos, financiados con sus propios capitales. De acuerdo a la Asocerv, nuestro país tiene un registro de 15 pequeñas cervecerías y 55 micros cervecerías de esta clase, que funcionan, principalmente, en Guayaquil, Quito, Ibarra, Cuenca, Loja y Manta (Brush, Daniel; Almeida, Luis, 2019)

El consumo de la cerveza en Manta, de acuerdo a una entrevista realizada a Melvyn Oswaldo Herrera Castro, reconocido comunicador social y administrador y distribuidor de cerveza en Manta por dos décadas (1970-1980), quien llegó a relacionarse con la industria cervecera al ser distribuidor de la compañía Cerveza Nacional de Guayaquil, cuando era una factoría pequeña y funcionaba donde ahora es el puerto Santa Ana. Comenzó siendo distribuidor en el suburbio de esa ciudad y gracias al buen servicio que se daba revolucionó la venta, pero, como nota curiosa narra, que, en aquel tiempo, la producción de cerveza era un poco escasa, lo que dio como resultado que la demanda superara la oferta (1974) Luego fue trasladado al cantón Chone, obviamente Manabí y aquí organizó, en el año 1976, 1977, no recuerda exactamente, la venta en todos los cantones. La distribución del servicio que hay actualmente ha cambiado, porque la compañía de cerveza nacional que era de inversionistas extranjeros, fue vendida al grupo Bavaria de Colombia y el grupo Bavaria la vendió a una transnacional de Europa y esta a su vez 
se fusionó con otro y la cervecería, que estaba a cargo de Ricardo Santana se mudó a Pascuales, donde era más grande el local, por el incremento de las ventas y se hizo una gran factoría que después se fusionó con cervecería Andina, que queda en Cumbayá, donde están las fuentes de agua, el agua es la materia prima para la cerveza, ahora pertenece a un gran monstruo mundial de la cerveza. Esa es su experiencia hasta el año 1988 cuando le convino separarse de esa industria y dedicarse a otras actividades. El primer mercado siempre fue Guayas, Manabí ocupó el segundo lugar por el número de habitantes, tenían muchos distribuidores para abarcar toda la provincia. Él fue asignado a Manta y desde Manta manejaba con otro colega este mercado, Portoviejo y el resto de los cantones los monitoreaba desde aquí. Es un buen negocio. Da réditos. El Lic. Herrera expresa que tuvo acciones en la empresa, porque los estimulaban con acciones y las vendió a muy buen precio. Es un negocio rentable, pero parece que ahora en estos últimos tiempos no lo es tanto, por la subida de impuestos. Al no ser un alimento de primera necesidad, al ser un refrescante, un estimulante (si se le puede decir), una bebida de segunda necesidad, entonces sí está de acuerdo en que debe pagar impuestos en una sociedad con tantos problemas económicos.

La clave de una buena cerveza está en la autenticidad, el buen sabor y yo diría el buen servicio y la publicidad que se haga, como en todo producto tiene que haber todo un engranaje y tradición. Es lo que pasaba con Pilsener que anteriormente, por ejemplo, no hacía publicidad deportiva y ahora la vemos en las camisetas de los equipos de fútbol. También la marca trumpet es respetable en el país, pero no tiene el alcance a pesar de ser una marca nacional, también la elaboran light, en distintas presentaciones. El mercado es exigente, es variable y la industria se ha ido acomodando a esto para obtener el rendimiento económico que necesita todo inversionista, más aún cuando es una industria que tiene más de cien años, que fue fundada por extranjeros; norteamericanos, ingleses, descendientes de los que hicieron el ferrocarril, de allí viene la historia de la cervecería en Guayaquil. Ellos pusieron, además de la cervecería, el frigorífico del Guayas para hacer hielo, eran industrias en ese tiempo desconocidas. En estos tiempos hubo una cerveza envasada en el Ecuador de marca alemana Loewenbrau, es una marca mundial, en otros países ha sido bien acogida pero aquí en el Ecuador no gustó, se deterioró; luego vino la competencia de otras marcas extranjeras como la Heineken que es mundial, vino una cerveza mexicana que es la corona, ya es cuestión de mercadeo y cómo se la penetre en las masas, masculina primeramente y con su segmento femenino luego. Pero en todo el Ecuador la cerveza que más se consume es la Pilsener, es una marca centenaria y ahora ya tiene sus variaciones por ejemplo tiene Pilsener Light que es muy consumida.

Melvin Herrera cuenta que la cerveza es una bebida popular, muy democrática (si cabe el término) al alcance de todos los bolsillos. Cuando fue creciendo, en esa metáfora de niño a hombre, como todos los jóvenes, piensa en tomarse su cervecita, fumarse un cigarrillo, en ese tiempo era parte de la masculinidad, después la siguió tomando socialmente. Es que la cerveza cae tan bien con casi todo; por ejemplo, con los mariscos, cuando hace calor, cuando se está entre amigos. En una comida como aperitivo o como bajativo. Otra competencia que va encontrando esta bebida tradicional y light, es la cerveza artesanal que, en otros países, como en Alemania, específicamente en Munich, la meca mundial de la cerveza, se hace un festival de 
ella, un homenaje, es realmente una fiesta. Es una "orgía" gastronómica (sin que se lo tome a mal): se tiene que tomar y consumir los productos alemanes; los chorizos, las comidas, he allí la demanda, el gusto de beberla, que está en la sangre de las tradiciones de la gente, obviamente acompañada de la música, espectáculos, distracciones, eso es mercadeo allá, al extremo que he visto que aquí en el Ecuador, en un hotel, específicamente, en el Hilton Colón se promociona la realización del Oktoberfest, por una semana. En Munich vi por primera cómo se consumía la cerveza artesanal, cada marca exhibía su producto, lo clásico era ir a unos sitios donde las meseras traían unos jarros inmensos de cerveza, cuatro o cinco en cada brazo, sacados de unos chimbuzos o recipientes, donde reposaba la cerveza artesanal, de diversos tipos, allá hay una riqueza de gustos. Esto que es costumbre en Europa se hizo moda por acá, los interesados copiaron esta idea de vender cerveza artesanal.

Para que un producto sea considerado artesanal, debe estar elaborado en su mayor parte de forma manual, con productos naturales, donde la creatividad, sabiduría y habilidad del artesano sea lo que sobresalga, donde la ayuda mecánica que utilice para obtener un resultado sea mínima y también maniobrada manualmente por él. Indico esto, para referirme a lo que realmente es una cerveza artesanal, es decir creada por artesanos, de acuerdo a sus propios conocimientos, siguiendo instrucciones heredadas o aprendidas de su entorno, de su familia, lo que le da identidad al producto, que hace que sea limitado, poco, pero que su contenido está libre de químicos, con sabores, aromas y texturas diferentes a las que son industrializadas. La cerveza artesanal, se somete a un fermentado natural, necesariamente es una composición de agua, lúpulo, malta y levadura, que debe su autenticidad a los sabores y olores de las frutas, de hierbas y especias que se emplean en su elaboración. En la obtención se esta clase de cerveza puede tomarse en cuenta el gusto del cliente, puede también responder a la innovación de un sector, de una comunidad, porque su volumen es pequeño, no responde a una industrialización donde lo que prevalece es el volumen mayoritario que trae ganancias mayoritarias. Es más, muchas veces la cerveza artesanal representa un costo mayor que las otras. Su calidad, el gusto personalizado y los sabores auténticos pueden subir su precio, pero aun así va ganando terreno en el mercado, aunque siempre está recibiendo codazos de las grandes compañías cerveceras multinacionales.

Con respecto a la Provincia de Manabí, hay publicidad, hay servicio, algunos restaurantes ya las venden. Es cuestión de que público la vaya aceptando. El empresario necesita crédito porque muchas veces no tiene la capacidad de invertir. Esto es un tema que hay que estudiar y analizar. Por ahora su consumo se limita a bares de clase media pero no a lugares o salones de barrios. La cerveza tiene fama de ser consumida por el de terno como por el sin zapatos, por decirlo así. En el consumo de las masas, después del agua, viene la gaseosa y luego la cerveza, sin tomar en cuenta al vino que tiene otro tipo de fenómeno. A base de servicio, precio, calidad y buena publicidad, toda la población la va a ir aceptando. Es preciso llegar a todas las clases sociales. En la época actual, hay emprendedores manabitas dedicados a esta actividad, que se acercan, de cierta manera, a lo que es una cerveza artesanal, pero sin cumplir con los parámetros que exige lo que por historia conocemos. Los hay en los cantones Portoviejo, Tosagua, Manta, en la parroquia y balneario Canoa. 
Para (Quintana, María; Aguilar, Jairo, 2018) el consumo de cerveza artesanal en Manabí es muy bajo todavía, son muy pocos quienes le tienen preferencia, por muchas razones, siendo la principal el valor monetario frente a la industrial.

Es importante también conocer el accionar de la Asociación de Cervecerías del Ecuador (Asocerv), instituida en el año 2013; para hacerlo hay que mirar su página web y observar que se mantienen datos interesantes sobre la promoción de la cerveza artesanal de calidad que se vende en el país, el fortalecimiento del sector productivo a través de nuevos emprendimientos que se están dando y sobre todo apoyar el consumo de esta bebida entre los ecuatorianos. También ha creado la Copa Artesanal de Cerveza Mitad del Mundo, con el fin de premiar la cerveza artesanal nacional e internacional, de mejor calidad, a través de un jurado calificador experto en la catación de este tipo de bebidas. Otra actividad importante que realizarán este año en la ciudad de Cuenca, es convocar a quienes se dedican a la fabricación, venta, distribución y a clientes del producto, para que, a través de charlas y capacitaciones, con la presencia de expositores expertos, se fortifique el área. Este mismo evento abarcará una feria donde se abre la posibilidad de exhibir a los mejores vendedores de la producción cervecera que se mueve en el país.

\section{Referencias}

Ariansen, Jaime, (2013). Los dioses y la gastronomía. Lima.

Ariansen, Jaime, (s.f.). https://www.historiacocina.com/paises/articulos/peru/chicha.htm. Obtenido de https://www.historiacocina.com/paises/articulos/peru/chicha.htm.

Avilés Pino, Efrén, (s.f.). http://www.enciclopediadelecuador.com/. Obtenido de http://www.enciclopediadelecuador.com/.

Brush, Daniel; Almeida, Luis. (2019). "estudio de factibilidad para la creación de la microempresa elaboradora de cerveza artesanal de sorgo "la serrana s.a." en Guayaquil. Obsevatorio de la economía latinoamerica.

Dueñas, C. (2010). Los viajes de los indios de Portoviejo a la Corte española. Conflictos interétnicos y territoriales. Procesos.

El descubrimiento de la cerveza. (s.f.). Obtenido de

http://www.cervebel.es/cerveza descubrimiento.htm (07/04/2020). 
ISSN: 2340-9096

https://dx.doi.org/10.17561/rtc.n18.4

Espuma latinoamericana. (2013) Revista IN agosto 2013. sección guía, 146-152. Obtenido de https://issuu.com/spafax/docs/112-in_agosto_web (07/04/2020).

Estrada, B. (2013). Importancia económica de los alemanes en Valparaíso, 1850 - 1915. Revista Scielo, Vol. 20 No. 2. https://doi.org/10.18232/alhe.v20i2.542

Gallegos, K., \& Santana, G. (Agosto de 2018). Fotoreportaje de las bebidas del patrimonio alimentario ecuatoriano en la ciudad de Quito. Quito, Pichincha, Ecuador: de la Universidad politécnica Salesiana.

González, F. (28 de Marzo de 2014). Cervecería Bavaria. Obtenido de www.bavaria.com.co/.

Hernández, J. L. (2 de Agosto de 2019). Los inicios de la cerveza en Colombia. Obtenido de Panorama cultural.com.

Loor, W. (1956). Manabí: Prehistoria y Conquista. Quito: Editorial La Salle.

Martínez, C. (2015). Análisis prospectivo al 2020 de la industria de la cerveza artesanal en el Ecuador como generadora de crecimiento económico. Tesis de maestría. Quito, Pichincha, Ecuador: Repositorio Institucional del Organismo de la Comunidad Andina, CAN.

Martínez, J. (2006). "Historia de la industria cervecera en Colombia" . Bucaramanga: Sic Editorial.

Mexicanos en Alemania. (20 de Septiembre de 2016). Obtenido de https://www.mexicanosenalemania.de/2016/09/20/cerveza-en-alemania/

Peralta, P. (2013). http://dspace.ucuenca.edu.ec/.

Quintana, María; Aguilar, Jairo. (2018). Evaluación de las cervezas artesanales de producción nacional y su maridaje con la cocina ecuatoriana. Innova - Revista de la Universidad Internacional del Ecuador, 344. https://doi.org/10.33890/innova.v3.n8.1.2018.828

Recio, G. (Octubre de 2004). El nacimiento de la industria cervecera en México, 1880-1910. Conferencia del Segundo Congreso Nacional de Historia Económica. San Diego, California, Estados Unidos: Center for US-Mexican Studies University.

Russo, C. (2008). Fábrica y localidad. La construcción de la identidad industrial: el caso de la cervecería y maltería Quilmes. H-industri@Revista de historia de la industria argentina y latinoamericana. 
ISSN: 2340-9096

https://dx.doi.org/10.17561/rtc.n18.4

Terán, E. (2015). Estudio para la creación de una empresa sustentable productora de malta y cerveza artesanal que fomente al desarrollo del sector agrícola ecuatoriano con la producción de cebada. Obtenido de Tesis de grado - ESPE.

Vera de Flaclis, M. (1994). Emigraciones transoceónicas. Los alemanes en América. 18501914. El caso argentino. Revista UCM - Universidad Nacional de Córdova, 68.

Villacreses, Elena; Rivadeneira, Miguel. (1996). La cebada en la alimentación humana del Ecuador. Revista Informativa del Instituto Nacional Autónomo INIAP. 